\title{
A decomposition analysis of change in skilled birth attendants, 2003 to 2008, Ghana demographic and health surveys
}

\author{
Samuel Bosomprah ${ }^{1 *}$, Genevieve Cecelia Aryeetey ${ }^{2}$, Justice Nonvignon ${ }^{2}$ and Richard M Adanu ${ }^{3}$
}

\begin{abstract}
Background: The single most critical intervention to improve maternal and neonatal survival is to ensure that a competent health worker with midwifery skills is present at every birth, and transport is available to a referral facility for obstetric care in case of an emergency. This study aims to describe changes in percentage of skilled birth attendants in Ghana and to identify causes of the observed changes as well as the contribution of different categories of mother's characteristics to these changes.

Method: This study uses two successive nationally representative household surveys: the 2003 and 2008 Ghana Demographic and Health Surveys (GDHS). The two datasets have comparable information on household characteristics and skilled attendants at birth at the time of the survey. The 2003 GDHS database includes information on 6,251 households and 3639 live births in the five years preceding the survey, whereas the 2008 GDHS database had information on11, 778 households and 2909 live births in the five years preceding the survey. A decomposition approach was used to explain the observed change in percentage of skilled birth attendants. Random-effects generalized least square regression was used to explore the effect of changes in population structure in respect of the mother's characteristics on percentage of skilled birth attendants over the period.

Results: Overall, the data showed absolute gain in the proportion of births attended by a health professional from $47.1 \%$ in 2003 to $58.7 \%$ in 2008, which represents $21.9 \%$ of gap closed to reach universal coverage. The increase in skilled birth attendants was found to be caused by changes in general health behaviour. The gain is regardless of the mother's characteristics. The structural change in the proportion of births in respect of birth order and mother's education had little effect on the change in percentage of skilled birth attendants.
\end{abstract}

Conclusion: Improvement in general health behaviour can potentially contribute to an accelerated increase in proportion of births attended by skilled personnel in Ghana.

\section{Background}

Improvement in maternal and neonatal survival remains a global priority. Globally, the total number of maternal deaths decreased from 543,000 in 1990 to 287,000 in 2010 [1]. Likewise, global maternal mortality ratio declined from 400 maternal deaths per 100,000 live births in 1990 to 210 in 2010. This represents an average annual decline of 3.1\% [1]. In Ghana, maternal survival has improved over the past 20 years albeit at a slow pace. According to the Maternal Mortality Estimation Inter-

\footnotetext{
* Correspondence: sbosomprah@ug.edu.gh

'Department of Biostatistics, School of Public Health, University of Ghana, Legon, Accra, Ghana

Full list of author information is available at the end of the article
}

Agency Group, maternal mortality ratio reduced from 580 per 100,000 live births in 1990 to 350 per 100,000 live births in 2010, representing a $40 \%$ reduction [1]. Three-quarters of all maternal deaths occur during delivery and the immediate post-partum period [2]. The common direct causes of maternal death in sub-Saharan Africa includes hemorrhage, sepsis, and pregnancy-induced hypertension [2]. On the other hand, neonatal mortality especially early neonatal mortality covering deaths in the first seven days after birth is of interest because the health interventions needed to address it generally relate to the mother. The major causes of early neonatal deaths in developing countries include prematurity, birth asphyxia, and infections [3]. 
The single most critical intervention to improve maternal and neonatal survival is to ensure that a competent health worker with midwifery skills is present at every birth, and transport is available to a referral facility for obstetric care in case of an emergency [4]. Increasing the proportion of births assisted by skilled personnel (Doctor, Nurse, Midwife, Auxiliary midwife, or Community health officer) is a central strategy for improving maternal and newborn survival in Ghana [4]. Skilled attendant at delivery is used as an indicator to track progress toward the Millennium Development Goal target of reducing maternal mortality by three-quarters between 1990 and 2015 [5]. According to the Ghana Demographic and Health Survey (GDHS), the percentage of skilled delivery increased from about 47\% in 2003 to $59 \%$ in 2008 [6,7]. Studies have shown that household wealth is associated with the rate of skilled birth attendant $[8,9]$. Other household factors related to poverty have been shown as important barriers to skilled birth attendant - illiteracy is a well-known barrier to recognizing birth-related complications and seeking appropriate health care $[10,11]$. However, little is known about the sources of this increase in the percentage of skilled birth attendants. This study aims to fill this knowledge gap by identifying causes of the observed changes as well as the contribution of different categories of mother's characteristics to these changes.

\section{Methods}

\section{Data sources}

This study used two successive nationally representative household surveys: the 2003 and 2008 GDHS [6,7]. The two datasets have comparable information on household characteristics and skilled attendants at birth at the time of the survey. The survey was designed to provide information to monitor the population and health situation in Ghana. The survey used a two-stage sample design to produce separate estimates for key indicators for each of the ten regions in Ghana. The first stage involved selecting clusters (called enumeration areas) from an updated master sampling frame constructed from the recent Ghana Population and Housing Census [12]. A complete household listing operation was conducted in all the selected clusters to provide a sampling frame for the second stage selection of households. The second stage of selection involved the systematic sampling of the households listed in each cluster. Each household selected was eligible for interview. In these surveys a household was defined as a person or a group of persons, related or unrelated, who live together in the same house or compound, share the same housekeeping arrangements, and eat together as a unit. Further details of the sample design and questionnaire are described elsewhere $[6,7]$.
The 2003 GDHS database included information on 6,251 households and 3639 live births in the five years preceding the survey, whereas the 2008 GDHS database had information on 11, 778 households and 2909 live births in the five years preceding the survey. The two surveys offered the opportunity for analysing coverage trends in the proportion of births attended by a skilled professional.

\section{Variables}

The exposure of interest for this study include mother's age at birth, birth order, maternal education [10,11], and socioeconomic status measured as household wealth index $[8,9]$. The household wealth index was estimated using an asset index. The asset index was constructed based on housing characteristics, household assets and possession of household consumer durables as well as access to clean water and improved sanitation using Principal Component Analysis technique, developed by Filmer and Pritchett [13]. Using rank methods, households were classified by wealth quintiles. The percentage of skilled birth attendants was defined as the proportion of live births in the five years preceding the survey delivered with the assistance of a skilled health professional (i.e. Doctor, Nurse, Midwife, Auxiliary midwife, or Community health officer).

\section{Statistical analysis}

Examining coverage trends is essential for assessing country progress. Information on trends requires at least two separate and comparable measurements at two points in time. A measure of progress - coverage gap - defined as how much coverage would need to increase from 2003 level to reach universal coverage was estimated to examine coverage trends. The change from 2003 to 2008 was then expressed as a percentage of this gap.

To explain the observed change in percentage of skilled birth attendants, the decomposition approach was used. Several regression decomposition approaches exist in the literature. The conventional Blinder-Oaxaca $[14,15]$ decomposition is based on two linear regression models that are fitted separately for the groups A and $B$ :

$$
\begin{aligned}
& Y_{A}=\boldsymbol{X}_{A} \boldsymbol{b}_{A}+e_{A} \\
& Y_{B}=\boldsymbol{X}_{B} \boldsymbol{b}_{B}+e_{B}
\end{aligned}
$$

For these models, Blinder [14] and Oaxaca [15] proposed the decomposition equations:

$$
Y_{A}-Y_{B}=\left(\boldsymbol{X}_{A}-\boldsymbol{X}_{B}\right) \boldsymbol{b}_{A}+\boldsymbol{X}_{B}\left(\boldsymbol{b}_{A}-\boldsymbol{b}_{B}\right)
$$


and

$$
Y_{A}-Y_{B}=\left(\boldsymbol{X}_{A}-\boldsymbol{X}_{B}\right) \boldsymbol{b}_{B}+\boldsymbol{X}_{A}\left(\boldsymbol{b}_{A}-\boldsymbol{b}_{B}\right)
$$

where $Y_{A}-Y_{B}$ is the mean outcome difference, and $\boldsymbol{X}_{A}$ and $X_{B}$ are mean vectors of the estimated coefficient vectors $\boldsymbol{b}_{A}$ and $\boldsymbol{b}_{B}$ for the two groups. In both equations, the first term on the right-hand side displays the difference in the outcome variable between the two groups due to differences in observable characteristics, whereas the second term shows the differential that is due to differences in coefficient estimates.

The approach used in this paper divides the change in percentage of skilled birth attendants into change in population structure and change in health behaviour and/or public health over the two time periods (or groups) 2003 to 2008 [16,17]. The population structure was defined as the ratio of number of births in each category or level of the exposure of interest to the sample size expressed as a percentage. The decomposition analyses were performed using national level data disaggregated by birth order, maternal education, and household wealth index. This method assumes that the historical change in the proportion of births attended by skilled professional depends on: 1) change in distribution of maternal education, birth order, maternal age and household wealth index over time (i.e. composition effect); 2) actual change in the proportion of births attended by skilled professional due to change in health behavior or improvement in public health (i.e. basic effect - the regression intercept when $\mathrm{x}=0(\boldsymbol{\alpha})$ ); and 3) variation of the proportion of births attended by skilled professional by exposure variables $(\boldsymbol{\beta})$, and the residual effect of other variables not considered as the error term $(\mu)$ [16]. This can be specified mathematically as follows:

$$
\begin{aligned}
\Delta S= & {\left[\sum \bar{s}_{j} * \Delta w_{j}\right]+\left[\sum \bar{w}_{j} * \Delta \alpha\right]+\left[\sum \bar{w}_{j} * x \Delta \beta\right] } \\
& +\left[\sum \bar{w}_{j} * x \Delta \mu\right]
\end{aligned}
$$

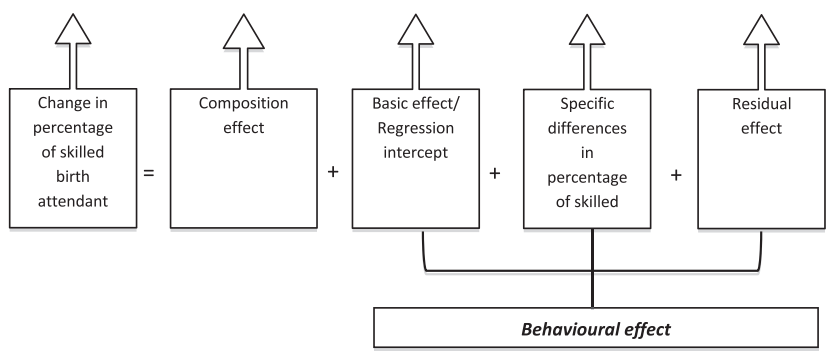

where $\Delta$ denotes change,

$S=$ percentage of skilled birth attendants,

$\bar{s}_{j}=$ arithmetic mean of percentage of skilled birth attendants for the $j^{\text {th }}$ category of the exposure variable, $w_{j}=$ the population structure for the $j^{\text {th }}$ category of the exposure variable.

$\bar{w}_{j}=$ arithmetic mean of the population structure for the $j^{\text {th }}$ category of the exposure variable,

$\Delta w_{j}=$ change in population structure expressed as a fraction for the $j^{t h}$ category of the exposure variable, and,

$x=$ the level of an exposure variable, e.g. maternal age was categorized as 1 ( $<20$ years), 2 (20-34 years), and 3 (35-49 years). So $x=1,2,3$.

The parameters in the mathematical model were estimated using an Excel spreadsheet program developed for this analysis and it is attached as an Additional file 1 to this manuscript [16].

In a separate analysis, the effect of changes in population structure in respect of the mother's characteristics (i.e. exposure of interest) on percentage of skilled birth attendants over the period was explored using the randomeffects generalized least squares (GLS) regression. Independent panel datasets were constructed for each of the characteristics (birth order, mothers education, and household wealth index). The panel was defined as the category of the exposure of interest and the order of observations within panel was considered ordered by the number of surveys (two in this case). For example, the birth order and maternal education datasets each contains eight observations, while the household wealth index dataset contains 10 observations. Each dataset contains the following variables: the panel identifier, time identifier, proportion of births in each category of the characteristics (i.e. population structure), and percentage of skilled birth attendants. The analyses were performed with Stata 12 for Mac (StataCorp, College Station, USA) [18].

The random-effects GLS regression model can be specified as follows:

$$
y_{i t}=\alpha+\beta w_{i t}+v_{i}+\epsilon_{i t}
$$

In this model, $v_{i}+\epsilon_{i t}$ is the residual that we have little interest in; the interest is to estimate $\beta$ (the effect of change in the structure of the exposure of interest). $w_{i t}$ is the population structure of the exposure of interest in the $i^{\text {th }}$ panel at survey time, $t . v_{i}$ is the unit-specific residual; it differs between units, but for any particular unit, its value is constant. $\epsilon_{i t}$ is the "usual" residual with the usual properties (mean 0, uncorrelated with itself, uncorrelated with $w$, uncorrelated with $v$, and homoskedastic) [18].

In all analyses, key survey characteristics such as sampling weight, stratification and clustering were accounted for.

\section{Ethics statement}

Ethical approval for the surveys was obtained from the Ghana Health Service. All participants gave a verbal or written consent by either appending their signature or 
thumb printed the consent form. Parental consent was obtained for children and where the child was capable, an assent was obtained from the child in addition to parental consent. Participants were informed about the aim of the study. Personal identifiers were not taken as part of data collection. The data available for this study cannot be linked to an individual who participated in the study. Approval was granted by Macro International to use the data for this study.

\section{Results}

Sample description and changes in percentage of skilled birth attendants

The 2008 GDHS recorded 2,909 births compared with 3,639 births in 2003. The more educated a woman was, the more likely she was to have delivered with the assistance of a skilled attendant but this population structure has changed over the period (Table 1). For instance, the proportion of births among mothers with no education decreased from $40.3 \%(1,466 / 3639)$ in 2003 to $32.7 \%$ $(952 / 2909)$ in 2008 and that among mothers with secondary or higher education increased from $5.2 \%$ $(191 / 3639)$ in 2003 to $9.1 \%(263 / 2909)$ in 2008. Delivery assistance by a health professional showed little association with women's age but it was related to the number of children a woman had. The more children a woman had the less likely she was to have a health professional attending her delivery. This structure had changed slightly over the period. For example, in 2003 about $20 \%$ (726/3639) of women had six or more children compared with $15.6 \%$ (455/2909) in 2008. Overall, the data showed absolute gain in the proportion of births attended by a health professional from $47.1 \%$ in 2003 to $58.7 \%$ in 2008. This gain represents $21.9 \%$ of gap closed to reach universal coverage (Table 1).

\section{Decomposition of change in percentage of skilled birth attendants}

The change in percentage of skilled birth attendants was decomposed by birth order, mother's education and household wealth index. This decomposition may contribute to the understanding of how the observed

Table 1 Changes in percentage of skilled birth attendants in the five years preceding the survey, 1998-2008, Ghana

\begin{tabular}{|c|c|c|c|c|c|}
\hline \multirow[t]{2}{*}{ Characteristics } & \multicolumn{2}{|c|}{ GDHS2003 (1998-2003) } & \multicolumn{2}{|c|}{ GDHS2008 (2003-2008) } & \multirow{2}{*}{$\begin{array}{l}\text { Proportion of } \\
\text { gap closed }^{2}\end{array}$} \\
\hline & $\begin{array}{l}\text { Number of birth } \\
\text { (\% of Total) }\end{array}$ & $\begin{array}{l}\text { Percentage of skilled } \\
\text { birth attendants }{ }^{1}(\mathrm{~A})\end{array}$ & $\begin{array}{l}\text { Number of birth } \\
\text { (\% of Total) }\end{array}$ & $\begin{array}{l}\text { Percentage of skilled } \\
\text { birth attendants }{ }^{1}(B)\end{array}$ & \\
\hline \multicolumn{6}{|l|}{ Maternal age } \\
\hline$<20$ & $411(11.3)$ & 48.4 & $333(11.4)$ & 52.2 & 7.4 \\
\hline $20-34$ & $2,507(68.9)$ & 47.7 & 2,079 (71.5) & 60.6 & 24.7 \\
\hline $35-49$ & $720(19.8)$ & 44.0 & $497(17.1)$ & 54.9 & 19.5 \\
\hline \multicolumn{6}{|l|}{ Birth order } \\
\hline 1 & $820(22.5)$ & 59.9 & $688(23.7)$ & 70.7 & 26.9 \\
\hline $2-3$ & $1,271(34.9)$ & 48.2 & $1,107(38.1)$ & 60.6 & 23.9 \\
\hline $4-5$ & $822(22.6)$ & 41.6 & $659(22.7)$ & 53.8 & 20.9 \\
\hline $6+$ & $726(20.0)$ & 36.8 & $455(15.6)$ & 42.6 & 9.2 \\
\hline \multicolumn{6}{|c|}{ Mother's education } \\
\hline None & $1,466(40.3)$ & 29.7 & $952(32.7)$ & 36.3 & 9.4 \\
\hline Primary & $843(23.2)$ & 44.4 & $722(24.8)$ & 54.6 & 18.3 \\
\hline Middle/JHS* & 1,139 (31.3) & 64.3 & 970 (33.4) & 74.4 & 28.3 \\
\hline Secondary+ & $191(5.2)$ & 89.4 & $263(9.1)$ & 92.4 & 28.3 \\
\hline \multicolumn{6}{|l|}{ Wealth Index } \\
\hline Poorest & $941(25.9)$ & 20.6 & $744(25.6)$ & 24.2 & 4.5 \\
\hline Second & $809(22.2)$ & 31.9 & $641(22.0)$ & 50.0 & 26.6 \\
\hline Middle & 721 (19.8) & 43.3 & 549 (18.9) & 64.8 & 37.9 \\
\hline Fourth & $617(17.0)$ & 73.1 & $560(19.3)$ & 81.7 & 32.0 \\
\hline Richest & $551(15.1)$ & 90.4 & 415 (14.3) & 94.6 & 43.8 \\
\hline Total & $3639(100)$ & 47.1 & 2909 (100) & 58.7 & 21.9 \\
\hline
\end{tabular}

${ }^{1}$ Skilled provider includes doctor, nurse, midwife, auxiliary midwife, and community health officer.

${ }^{2} \%$ gap closed $=[(B)-(A)]^{*} 100 /[100-(A)]$.

Note: $\%$ of Total represents the population structure.

*JHS represents junior high school. 
Table 2 Decomposition of changes in percentage of skilled birth attendants, 1998-2008, Ghana

\begin{tabular}{|c|c|c|c|c|c|c|}
\hline & \multirow[t]{2}{*}{ Composition } & \multicolumn{4}{|c|}{ Behaviour effect } & \multirow[b]{2}{*}{ Contribution } \\
\hline & & Base & Differentiation & Error & Total & \\
\hline \multicolumn{7}{|l|}{ Birth order } \\
\hline 1 & 0.784 & 2.911 & -0.347 & -0.069 & 2.495 & $28.3 \%$ \\
\hline $2-3$ & 1.741 & 4.599 & -1.095 & 1.022 & 4.526 & $54.0 \%$ \\
\hline $4-5$ & 0.048 & 2.854 & -1.019 & 0.929 & 2.763 & $24.2 \%$ \\
\hline $6+$ & -1.747 & 2.243 & -1.068 & -0.142 & 1.032 & $-6.2 \%$ \\
\hline Overall & $7.1 \%$ & $108.3 \%$ & $-30.3 \%$ & $14.9 \%$ & $92.9 \%$ & $100 \%$ \\
\hline \multicolumn{7}{|c|}{ Mother's education } \\
\hline None & -2.508 & 3.322 & -0.401 & -0.511 & 2.409 & $-0.9 \%$ \\
\hline Primary & 0.792 & 2.184 & -0.528 & 0.792 & 2.448 & $27.9 \%$ \\
\hline Middle/JHS* & 1.456 & 2.944 & -1.068 & 1.391 & 3.267 & $40.7 \%$ \\
\hline Secondary+ & 3.545 & 0.651 & -0.315 & -0.122 & 0.215 & $32.4 \%$ \\
\hline Overall & $28.3 \%$ & $78.3 \%$ & $-19.9 \%$ & $13.3 \%$ & $71.7 \%$ & $100 \%$ \\
\hline \multicolumn{7}{|c|}{ Household wealth index } \\
\hline Poorest & -0.067 & 3.311 & -0.206 & -2.178 & 0.927 & $7.4 \%$ \\
\hline Second & -0.082 & 2.842 & -0.354 & 1.512 & 4.000 & $33.8 \%$ \\
\hline Middle & -0.486 & 2.488 & -0.464 & 2.136 & 4.160 & $31.7 \%$ \\
\hline Fourth & 1.780 & 2.334 & -0.581 & -0.192 & 1.561 & $28.8 \%$ \\
\hline Richest & -0.740 & 1.890 & -0.588 & -0.685 & 0.617 & $-1.1 \%$ \\
\hline Overall & $2.9 \%$ & $110.2 \%$ & $-18.8 \%$ & $5.1 \%$ & $96.5 \%$ & $100 \%$ \\
\hline
\end{tabular}

*JHS represents junior high school.

changes related to variations in the survey population structure or to changes in public health and/or changes in behaviour. In general, the decomposition results indicated that health behaviour were the principal source of the gain in percentage of skilled birth attendants between 2003 and 2008 regardless of the exposure variable (Table 2, column Total). The analysis of behavioral effect suggested that the observed gain in percentage of skilled birth attendants was global (not specific to some socioeconomic characteristics). In other words, the observed changes were due to the general improvement in health behaviour in Ghana. The differentiation effect, the error terms, and composition effect were negligible. The contributions of each socioeconomic category in the overall gain in percentage of skilled birth attendants were also presented (Table 2, column Contribution). Depending on the exposure variable, the increase in percentage of skilled birth attendants in the following groups had contributed more to the observed changes: babies whose mothers had Middle or Junior High School education $(40.7 \%)$, babies whose mothers had two to three births (54\%), and babies born to "middle" class families (Table 2, column Contribution). It is however interesting to note that babies born to "richest" class families (Contribution $=-1.1 \%$ ) and those whose mothers had six or more births (Contribution $=-6.2 \%$ ) did not contribute to the observed change.

\section{Effect of change in population structure on percentage of skilled birth attendants}

The structural change in the proportion of births in respect of birth order and mother's education had little effect on the change in percentage of skilled birth attendants. Specifically, there was no evidence of the effect of structural change in the proportion of births in respect

Table 3 Random-effect generalised least square regression of the effect of change in population structure on percentage of skilled birth attendants

\begin{tabular}{lllr}
\hline $\begin{array}{l}\text { Change in proportion of } \\
\text { births in respect of: }\end{array}$ & $\begin{array}{l}\text { Change in percentage of skilled } \\
\text { birth attendants }(\mathbf{9 5 \%} \mathbf{C l})\end{array}$ & $\begin{array}{l}\text { Z statistic; } \\
\text { P-value }\end{array}$ & $\boldsymbol{v}$ \\
\hline Birth order & $0.58(-0.88,2.04)$ & $0.78 ; 0.44$ & 10.68 \\
Mother's education & $-0.96(-2.26,0.33)$ & $-1.5 ; 0.14$ & 17.68 \\
Household wealth index & $-6.45(-8.10,-4.79)$ & $-7.6 ;<0.0001$ & 0.44 \\
\hline
\end{tabular}


of birth order (coefficient $=0.58 ; 95 \% \mathrm{CI}=-0.88,2.04$; $\mathrm{P}=0.44$ ) and mother's education (coefficient $=-0.96$; 95\% CI $=-2.26,0.33$; P-value $=0.14$ ) on change in percentage of skilled birth attendants (Table 3). There was however strong evidence that structural change in the proportion of births in respect of socioeconomic status measured by household wealth index had significant effect on the change in percentage of skilled birth attendants (coefficient $=-6.45 ; 95 \% \mathrm{CI}=-8.10,-4.79$; P-value $<0.0001)$.

\section{Discussion}

This study aims to describe changes in percentage of skilled birth attendants and to identify causes of the observed changes as well as the contribution of different categories of mother's characteristics to these changes. The results showed that the gain in percentage of skilled birth attendants observed in Ghana between 2003 and 2008 is regardless of the mother's characteristics, suggesting that the observed changes are due to the general improvement in health behaviour. The findings are consistent with studies, which showed that socio-cultural factors are important predictors of skilled delivery. For example, in a literature review of the determinants of delivery service use, Gabrysch and Campbell 2009 found that perceived benefit and need affect the decision to seek delivery care [19]. The health behaviour especially the perceived benefit and need relates to a number of factors influencing the perception of how a facility delivery with skilled attendants would benefit mother and newborn and or how big the personal need for such care is. This perception is shaped by general awareness of the dangers of childbirth and interventions available at health facilities. It is also shaped by individual past experiences with pregnancy, childbirth and health services, as well as by risk assessment of the index pregnancy.

Specific knowledge about the risks of childbirth and the benefits of skilled attendant at delivery can increase preventive care seeking. Similarly, recognition of danger signs and knowledge about availability of key maternal and newborn interventions can increase care seeking for obstetric complications. Most studies like the GDHS on use of delivery care are cross-sectional and it is difficult to establish temporal effect. This then is a limitation of such studies. Studies have shown that women who know danger signs in pregnancy or who are told about complications at antenatal care are more likely to deliver in a health facility [20,21]. The 2008 GDHS collected qualitative data on socio-cultural factors impeding women to seek skilled care when pregnant and the results showed that the major concerns included getting money for treatment, availability of drugs as well as the availability of a health care provider [6]. Other factors mentioned were in respect of having to seek permission to go for treatment as well as lack of a female provider and not wanting to go alone. These findings corroborate the important contribution of general health behaviour in the observed change in percentage of skilled birth attendants in Ghana over the period 2003 to 2008.

The results have implications for consideration of culturally acceptable options that increase demand or use of health workers with lesser skill levels. The creative alternatives such as the community-based health planning and services or use of mobile teams of at least one female community health officer that can provide services should be consolidated. Communication for behavioral Impact [22] strategies would facilitate new ways of providing maternity services by increasing awareness and demand for safe care during delivery. Antenatal care (ANC) visits constitute one of the few times women in many resource-poor settings seek care for their own health [23], and, represent an important opportunity to help women best prepare for birth, as well as inform them about pregnancy-related complications, and the advantages of skilled delivery care [24,25]. Several studies showed that women who attend ANC are more likely to seek skilled delivery care [26-29].

\section{Conclusion}

Improvement in general health behavior can potentially contribute to an accelerated increase in proportion of births attended by skilled personnel in Ghana. Skilled delivery care would translate into improved maternal and newborn survival.

\section{Availability of supporting data}

The data used for this study can be accessed through the following links:

http://www.measuredhs.com/publications/publicationFR221-DHS-Final-Reports.cfm.

http://www.measuredhs.com/publications/publicationFR152-DHS-Final-Reports.cfm.

\section{Additional file}

Additional file 1: Decomposition analysis spreadsheet 21 Sept 2014.

\section{Competing interests}

The authors declare that they have no competing interests.

\section{Authors' contributions}

SB, GCA, JN and RMA conceived the study. SB designed the study, analysed the data and drafted the manuscript. GCA, JN, and RMA reviewed the manuscript. All authors approved the final draft for submission.

\section{Acknowledgements}

The preparation of this manuscript was supported by the Building Stronger Universities Initiative - Platform on Human Health of the University of Ghana, funded by the Danish Government.

The authors are grateful to Macro International who provided financial and technical assistance for the survey, which data has been used in this study, 
through the USAID-funded MEASURE DHS programme. Local costs for the survey were partially funded by the Ministry of Health $(\mathrm{MOH})$, the Ghana Statistical Service (GSS), the Ghana AIDS Commission (GAC), UNICEF, UNFPA, and DANIDA.

\section{Author details}

${ }^{1}$ Department of Biostatistics, School of Public Health, University of Ghana, Legon, Accra, Ghana. ${ }^{2}$ Department of Health Policy, Planning and Management, School of Public Health, University of Ghana, Legon, Accra, Ghana. ${ }^{3}$ School of Public Health, University of Ghana, Legon, Accra, Ghana.

Received: 12 August 2013 Accepted: 5 December 2014

Published online: 24 December 2014

\section{References}

1. Chou D, Inoue M, Mathers C, Moller A-B, Oestergaard M, Say L, Mill S, Suzuki E, Wilmoth J: Trends in Maternal Mortality: 1990 to 2010. Geneva, Switzerland: WHO Document Production Services; 2010:25-40.

2. Requejo J, Bryce J, Victora C: Countdown to 2015: Building a Future for Women and Children. 2012:111.

3. Liu L, Johnson HL, Cousens S, for the Child Health Epidemiology Reference Group of WHO and UNICEF, et al: Global, regional, and national causes of child mortality: an updated systematic analysis for 2010 with time trends since 2000. Lancet 2012, 379:2151-2161.

4. Ministry of Health $(\mathrm{MoH})$, Government of Ghana, United Nations Country Team in the Republic of Ghana: MDG acceleration framework and country action plan, maternal health. July 2011

5. World Health, Organization: Proportion of Births Attended by a Skilled Health Worker. In. Avenue Appia 20, 1211 Geneva 27, Switzerland: Department of Reproductive Health and Research; 2008 update: 1

6. Ghana Statistical Service GSS, Ghana Health Service GHS, ICF Macro: Ghana Demographic and Health Survey 2008. Accra, Ghana: GSS, GHS, and ICF Macro; 2009.

7. Ghana Statistical Service GSS, Noguchi Memorial Institute for Medical Research NMIMR, ORC Macro: Ghana Demographic and Health Survey 2003. Calverton, Maryland: GSS, NMIMR, and ORC Macro; 2004.

8. Thind A, Banerjee $\mathrm{K}$ : Home deliveries in Indonesia: who provides assistance? J Community Health 2004, 29:285-303.

9. Falkingham J: Inequality and changes in women's use of maternal health-care services in Tajikistan. Stud Fam Plann 2003, 34:32-43.

10. Zahid GM: Mother's health-seeking behaviour and childhood mortality in Pakistan. 1996;35(4pt 2)719-731. Pak Dev Rev 1996, 35(4pt2):719-731.

11. Fathalla MF: Reproductive health: a global overview. Ann N Y Acad Sci 1991, 626:1-10.

12. Ghana Statistical Service: Population and Housing Census. In.: Accra, Ghana; 2000.

13. Filmer $D$, Pritchett $L H$ : Estimating wealth effects without expenditure data-or tears: an application to educational enrollments in states of India. Demography 2001, 38:115-132.

14. Blinder AS: Wage discrimination: Reduced form and structural estimates. J Human Resour 1973, 8:436-455.

15. Oaxaca R: Male-female wage differentials in urban labor markets. Int Econ Rev 1973, 14:693-709.

16. Emina JBO, Kandala N-B: Accounting for recent trends in the prevalence of diarrhoea in the Democratic Republic of Congo (DRC): results from consecutive cross-sectional surveys. BMJ Open 2012, 2.

17. Romo V: Decomposition analysis in demography. In. PhD Dissertation Groningen, the Netherlands: Rijksuniversiteit Groningen 2003

18. StataCorp: Stata: Release 12. Statistical Software. College Station, TX: StataCorp LP. 2011:454-471.

19. Gabrysch S, Campbell OMR: Still too far to walk: literature review of the determinants of delivery service use. BMC Pregnancy Childbirth 2009, 9:34.

20. Stekelenburg J, Kyanamina S, Mukelabai M, Wolffers I, van Roosmalen J: Waiting too long: low use of maternal health services in Kalabo, Zambia. Trop Med Int Health 2004, 9(3):390-398.

21. Gage AJ: Barriers to the utilization of maternal health care in rural Mali. Soc Sci Med 2007, 65(8):1666-1682.

22. World Health, Organisation: Manual for Planning Communication-forBehavioural-Impact (COMBI) Programmes for Health. In.: Communicable Diseases (CDS) Division; 2006.
23. Carroli G, Rooney C, Villar J: How effective is antenatal care in preventing maternal mortality and serious morbidity? An overview of the evidence. Paediatr Perinat Epidemiol 2001, 15(suppl 1):1-42.

24. Campbell OMR, Graham WJ: Strategies for reducing maternal mortality: getting on with what works. Lancet 2006, 368:1284-1299.

25. Lindmark $G$, Berendes $H$, Meirik $O$ : Antenatal care in developed countries. Paediatr Perinat Epidemiol 1998, 12(suppl 2):4-6.

26. Bloom SS, Lippeveld T, Wypij D: Does antenatal care make a difference to safe delivery? A study in urban Uttar Pradesh, India. Health Policy Plan 1999, 14(1):38-48.

27. Yanagisawa S, Oum S, Wakai S: Determinants of skilled birth attendance in rural Cambodia. Trop Med Int Health 2006, 11(2):238-251.

28. WHO/UNICEF: Antenatal Care in Developing Countries: Promises, Achievements and Missed Opportunities. Analysis of Trends, Levels and Differentials 1990-2001. Geneva: WHO; 2003.

29. Stanton C, Blanc AK, Croft T, Choi Y: Skilled care at birth in the developing world: progress to date and strategies for expanding coverage. J Biosoc Sci 2007, 39:109-120.

\section{Submit your next manuscript to BioMed Central and take full advantage of:}

- Convenient online submission

- Thorough peer review

- No space constraints or color figure charges

- Immediate publication on acceptance

- Inclusion in PubMed, CAS, Scopus and Google Scholar

- Research which is freely available for redistribution

Submit your manuscript at www.biomedcentral.com/submit
C) BioMed Central 